\title{
First Record of Hemichela nanhaiensis (Pycnogonida: Ammotheidae) from Japanese Waters, with the First Description of Females
}

\author{
Yushi Hosoda ${ }^{1,3}$, Shinri Tomioka ${ }^{1,2}$, and Keiichi Kakui ${ }^{1}$ \\ ${ }^{1}$ Graduate School of Science, Hokkaido University, Sapporo, Hokkaido 060-0810, Japan \\ E-mail: hosoda-uc-desu@eis.hokudai.ac.jp \\ ${ }^{2}$ Present address: Rishiri Town Museum, Senhoshi, Rishiri Is., Hokkaido 097-0311, Japan \\ ${ }^{3}$ Corresponding author
}

(Received 8 December 2017; Accepted 25 May 2018)

\begin{abstract}
We report the first record of the ammotheid pycnogonid species Hemichela nanhaiensis Wang et al., 2015, from Japanese waters. Four specimens of $H$. nanhaiensis were collected from the East China Sea at depths of 405-635 m, including the first females ever found. We redescribe male and female H. nanhaiensis from these specimens. We found that $H$. nanhaiensis is sexually dimorphic in the number of tiny lateral outgrowths on the lateral processes; length of the lateral process tubercles and oviger articles 4 and 5; ratio of the terminal claw to article 10 in the oviger; presence or absence of a proximal reversed spine on oviger article 5; thickness of the leg femur; and number of gonopores.
\end{abstract}

Key Words: Pantopoda, sea spider, deep-sea, new record, Japan, Pacific.

\section{Introduction}

The pycnogonid genus Hemichela Stock, 1954 is one of 21 genera in the family Ammotheidae Dohrn, 1881 (Sabroux et al. 2017). Hemichela shares many morphological characters with the genus Paranymphon Caullery, 1896, including wellseparated lateral processes, a uniarticulate scape, a 7-articulate palp, 10-articulate ovigers with a terminal claw, and a propodus without heel spines or auxiliary claws, but differs in lacking the immovable finger on the chelifore. Hemichela contains three species: H. micrasterias Stock, 1954; H. longiunguis Staples, 1982; and H. nanhaiensis Wang et al., 2015. The type species $H$. micrasterias, was described from the Java Sea at $35 \mathrm{~m}$ depth (Stock 1954) and has subsequently been reported from the Visayan Sea, Flores Sea, Pacific Ocean off Japan, and South China Sea at depths of 20-657 m (Stock 1985; Child 1988; Nakamura and Child 1990, 1991; Bamber 1992). Hemichela longiunguis was reported from estuaries in Queensland, Australia at depths of $1.2-5.8 \mathrm{~m}$ (Staples 1982). Hemichela nanhaiensis was described from a single male collected from the South China Sea at $1317.5 \mathrm{~m}$ depth (Wang et al. 2015).

In 2009 and 2011, we collected four Hemichela individuals from deep water in the East China Sea; these represented two males and two females of $H$. nanhaiensis. This is the second record for the species and the first record of its females. Here we redescribe $H$. nanhaiensis based on our specimens, with the first description for females.

\section{Materials and Methods}

Pycnogonids were collected by beam trawl with plankton nets (Akiyama et al. 2008) during cruises N276 and N342 of the TR/V Nagasaki-maru (Nagasaki University) in 2009 and 2011, respectively, and fixed and preserved in 99\% ethanol. Appendages were detached from the trunk by using chemically sharpened tungsten needles, mounted on glass slides in glycerin, and observed with an Olympus BX51 microscope. Body parts were observed with a Nikon SMZ 1500 microscope. Illustrations were prepared with CLIP STUDIO PAINT PRO ver. 1.6.6 (CELSYS, Japan) from draft line drawings made using a drawing tube. Morphological terminology follows Child (1979), except that the term 'article' is used instead of "segment" in all appendages; the formula for the number of compound spines on the oviger follows Wang et al. (2015) (e.g., the formula ' $3: 2: 1: 1$ ' indicates that articles 7-10 have three, two, one, and one spines, respectively). Measurements were made axially (dorsally for the trunk; laterally for the palp, proboscis, and legs) and are presented in millimeters. Measurements for congeners were obtained from original descriptions or measured from original illustrations. Our specimens have been deposited in the Invertebrate Collection of the Hokkaido University Museum (ICHUM), Japan. 

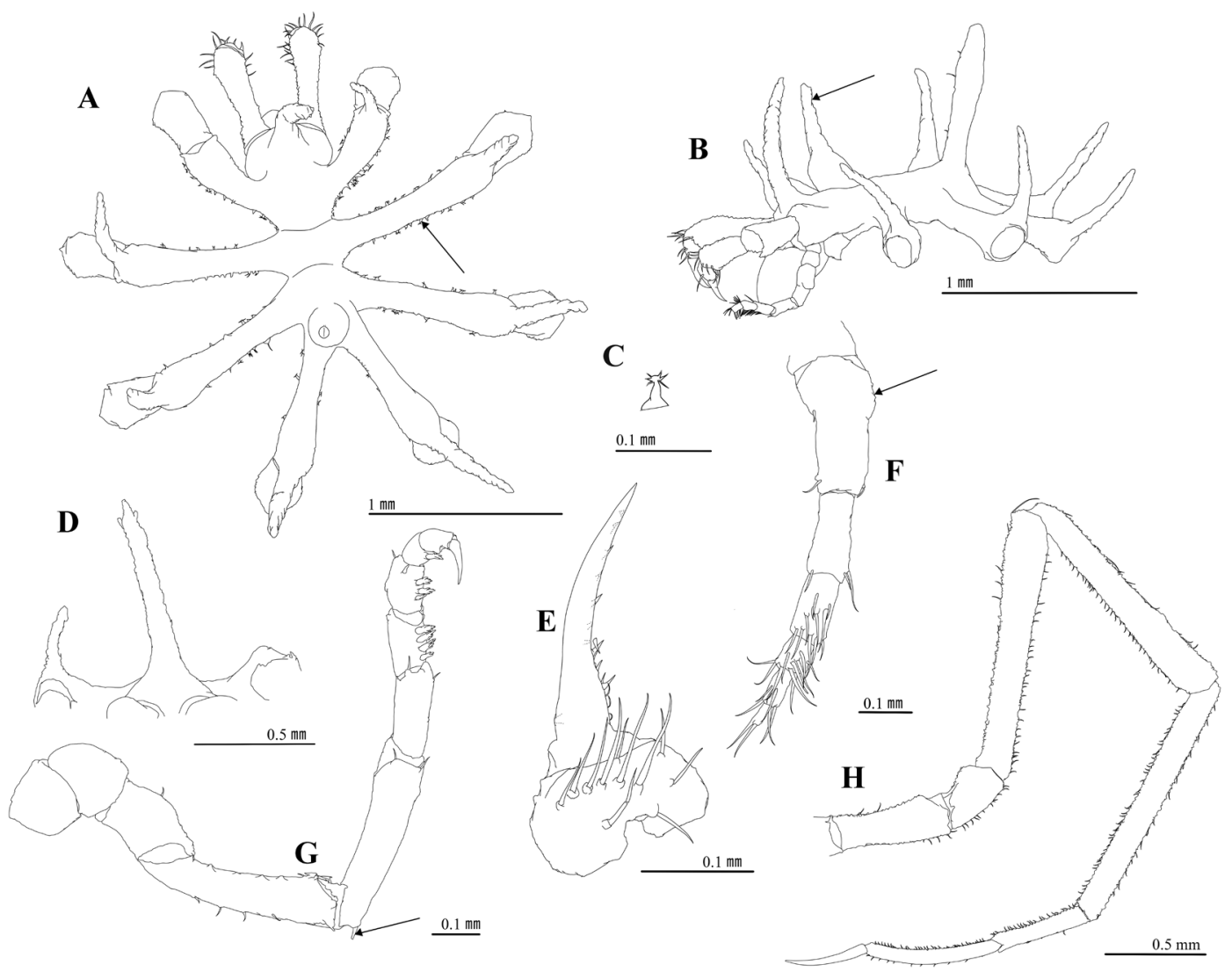

Fig. 1. Hemichela nanhaiensis Wang et al., 2015, male (ICHUM-5437): A, trunk, dorsal view (arrow, tiny lateral outgrowth bearing distal spinules); B, trunk, lateral view (arrow, dorsodistal tubercle); C, tiny lateral outgrowth bearing distal spinules; D, ocular tubercle, front view; E, chela; F, palp (arrow, outer swelling); G, oviger (arrow, proximal reversed spine); H, leg 3.

\section{Systematics}

Family Ammotheidae Dohrn, 1881

Genus Hemichela Stock, 1954

Hemichela nanhaiensis Wang et al., 2015

(Figs 1, 2)

Material examined. 1 female (ICHUM-5435), $32^{\circ} 14.97^{\prime} \mathrm{N}, 129^{\circ} 28.32^{\prime} \mathrm{E}$, west of Hirajisone, East China Sea, $405 \mathrm{~m}, 7$ March 2009. 1 male carrying eggs (ICHUM5436), $28^{\circ} 33.605^{\prime} \mathrm{N}, 127^{\circ} 02.676^{\prime} \mathrm{E}$, off Amami, East China Sea, 619-635 m, 17 November 2011. 1 male (ICHUM-5437), $28^{\circ} 33.576^{\prime} \mathrm{N}, 127^{\circ} 02.616^{\prime} \mathrm{E}$, off Amami, East China Sea, 625-629 m, 18 November 2011. 1 female (ICHUM-5438), $28^{\circ} 33.601^{\prime} \mathrm{N}, 127^{\circ} 02.457^{\prime} \mathrm{E}$, off Amami, East China Sea, $608-618 \mathrm{~m}, 19$ November 2011. All specimens were collected by K. Kakui.

Amended diagnosis. Lateral processes long, width across second processes more than 1.45; outgrowths on lateral processes unbranched, each bearing distal spinules; movable finger of chelifore with 12 teeth.

Description of male (ICHUM-5437). Measurements: length of trunk (from chelifore insertion to base of fourth lateral processes) 1.18; width across second lateral processes 2.04; proboscis length 0.52 ; length of palp articles 2-7: 0.25 , $0.15,0.13,0.06,0.07,0.04$; length of oviger articles $1-10$ and terminal claw: $0.12,0.11,0.13,0.38,0.34,0.18,0.11,0.10$, $0.04,0.06,0.09$; length of articles on leg 3 (from coxa 2; including claw): $0.53,0.28,1.26,1.18,1.23,0.45,0.64,0.40$.

Trunk (Fig. 1A-C) with indistinct segment boundaries; covered with many tiny papillae. Lateral processes long, well-spaced, each with long, tapering, dorsodistal tubercle (Fig. 1B arrow) and many tiny, unbranched lateral outgrowths each bearing distal spinules (Fig. 1A arrow; Fig. $1 \mathrm{C})$; tubercle length twice as long as diameter of widest portion of lateral process. Ocular tubercle (Fig. 1D) tall, erect, with pair of tiny tubercles at tip. Eyes absent. Proboscis short, tapering distally. Abdomen long, erect, with few setae.

Chelifore (Fig. 1B, E) scape uniarticulate, with dorsodistal setae. Chela palm (Fig. 1E) with dorsal setae. Finger curved, with 12 teeth.

Palp (Fig. 1F) 7-articulate. Article 2 with distal seta and outer swelling (Fig. 1F arrow), articles 4-7 with ventral setae.

Oviger (Fig. 1G) with 10 articles and terminal claw. Articles 1-3 with few setae, article 5 with proximal reversed spine (Fig. 1G arrow). Articles 7-10 of left oviger with compound spines in formula $4: 3: 1: 1$ (right oviger damaged during dissection).

Legs (Fig. 1H) slender, with dorsal and ventral setae (more setae on ventral side); femur without cement gland; propodus without heel spines or auxiliary claws. Genital pore present on coxa 2 of leg 4 . 


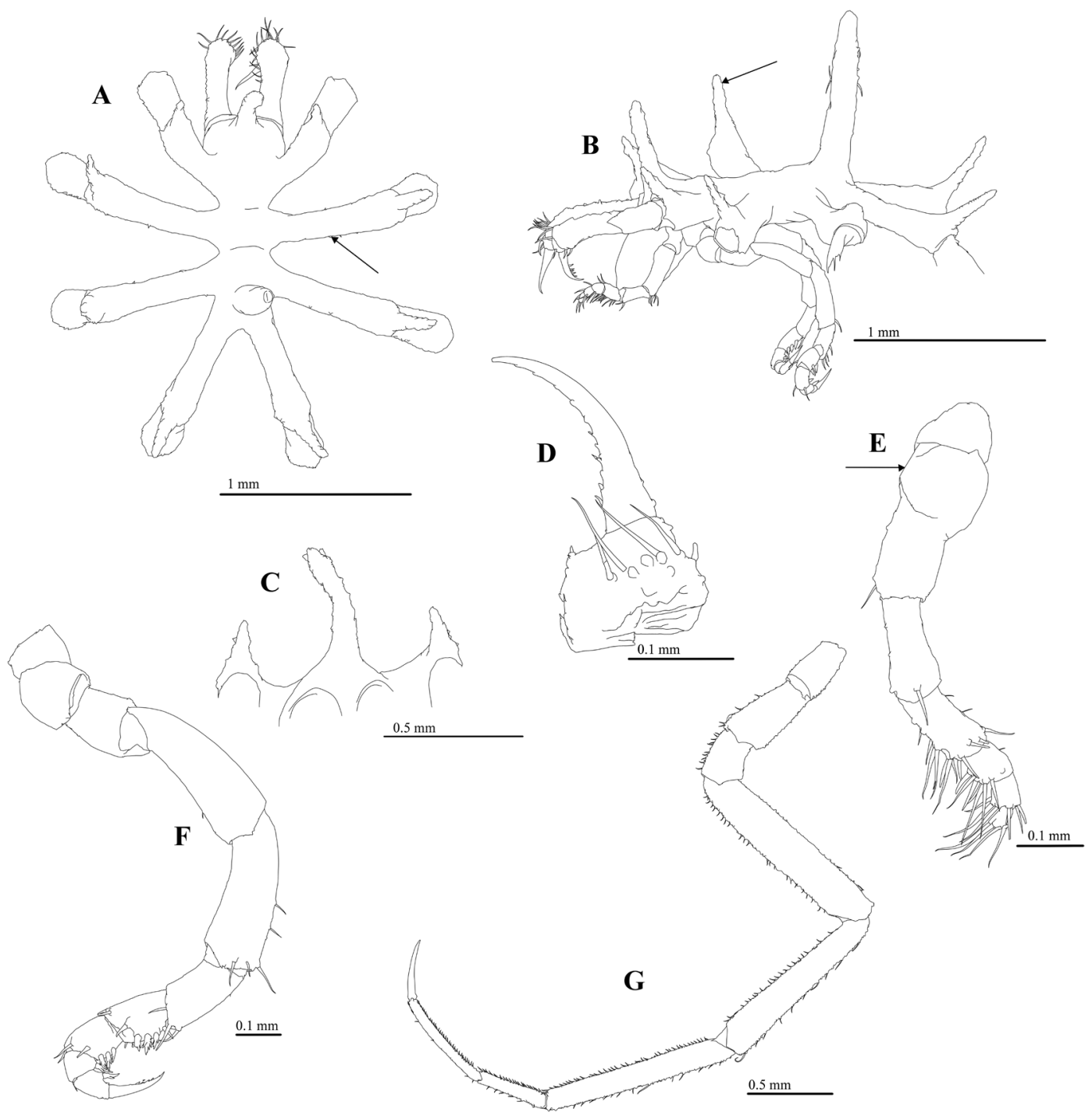

Fig. 2. Hemichela nanhaiensis Wang et al., 2015, female (ICHUM-5438): A, trunk, dorsal view (arrow, tiny lateral outgrowth bearing distal spinules); B, trunk, lateral view (arrow, dorsodistal tubercle); C, ocular tubercle, front view; D, chela; E, palp (arrow, outer swelling); F, oviger; G, leg 3 .

Description of female (ICHUM-5438). Measurements: length of trunk (from chelifore insertion to base of fourth lateral processes) 1.10; width across second lateral processes 1.67; proboscis length 0.44 ; length of palp articles 1-7: 0.07, $0.24,0.15,0.11,0.06,0.04,0.04$; length of oviger articles $1-10$ and terminal claw: $0.06,0.12,0.30,0.36,0.30,0.15$, $0.12,0.09,0.05,0.06,0.13$; length of articles on leg 3 (from coxa 1; including claw): $0.34,0.45,0.28,1.14,1.06,1.09$, $0.39,0.61,0.35$.

Trunk (Fig. 2A, B) with indistinct segment boundaries; covered with many tiny papillae. Lateral processes long, well-spaced, each with long, tapering, dorsodistal tubercle (Fig. 2B arrow) and several tiny, unbranched lateral outgrowths each bearing distal spinules (Fig. 2A arrow); tubercle length less than twice diameter of widest portion of lateral process. Ocular tubercle (Fig. 2C) tall, erect, with pair of tiny tubercles at tip. Eyes absent. Proboscis short, tapering distally. Abdomen long, erect, with few setae.

Chelifore (Fig. 2B, D) scape uniarticulate, with dorso- distal setae. Chela palm (Fig. 2D) with dorsal setae. Finger curved, with 12 teeth.

Palp (Fig. 2E) 7-articulate. Article 2 with distal seta and outer swelling (Fig. 2E arrow), articles $4-7$ with ventral setae.

Oviger (Fig. 2F) with 10 articles and terminal claw. Articles 1-3 with few setae. Articles 7-10 with compound spines in formula $4: 3: 1: 1$ (right), $3: 3: 1: 1$ (left).

Legs (Fig. 2G) slender, with dorsal and ventral setae (more setae on ventral side); femur without cement gland; propodus without heel spines or auxiliary claws. Genital pores present on coxa 2 of all legs.

Sexual dimorphism and individual variation. Compared to males, females have fewer tiny lateral outgrowths, a shorter ocular tubercle, shorter dorsodistal tubercles on the lateral processes, shorter oviger articles 4 and 5 , a longer terminal claw relative to oviger article 10 (1.12-1.30 in males; 1.72-1.87 in females), a thicker femur, and fewer genital pores (on leg 4 in males, legs 1-4 in females). Females lack 
the proximal reversed spine on oviger article 5.

The following character varied among specimens: the number of compound spines on oviger articles 7-10 showed in the formula was $4: 3: 1: 1$ (left in ICHUM-5437; right in ICHUM-5435), 3:3:1:1 (left in ICHUM-5435), or 3:2:1:1 (both in ICHUM-5436 and -5438).

Remarks. Although our male specimens shared almost all characters with the holotype, they differed from the male individual in Wang et al. (2015) in the number of compound spines on oviger articles $7-10(4: 3: 1: 1$ or $3: 2: 1: 1$ versus $3: 2: 1: 1)$ and the length ratio of the terminal claw to article 10 in the oviger (1.12-1.30 versus 1.0). Furthermore, the holotype has genital pores on legs 3 and 4, whereas we observed them on leg 4 only. Male genital pores have been observed on legs 1-4 in H. longiunguis (Staples 1982), thus differing in number and position from $H$. nanhaiensis from both localities. This raises the question whether, if the number and position of male (and female) genital pores are important characters in species discrimination in this genus, our specimens are indeed conspecific with Wang's et al. (2015) specimen. To confirm conspecificity, more specimens from both localities and molecular genetic data will be needed.

Wang et al. (2015) measured the width across the second lateral processes of the holotype as $3.49 \mathrm{~mm}$, which he noted was distinctly larger in body size than its congeners. Our specimens were markedly smaller than Wang's, 1.90$2.04 \mathrm{~mm}$ in males and $1.45-1.67 \mathrm{~mm}$ in females. However, based on the $1 \mathrm{~mm}$ scale bar accompanying Wang's fig. 1B, the comparable measurement of the holotype is only about $1.85 \mathrm{~mm}$, which is close to the range in our specimens, indicating an error in the original description. In any case, the other two congeners are smaller in size than H. nanhaiensis from either locality; the width across second lateral processes is $0.92-1.00 \mathrm{~mm}$ in male H. micrasterias (Stock 1954, 1985), and $1.03 \mathrm{~mm}$ and $0.87 \mathrm{~mm}$ in male and female H. longiunguis, respectively (Staples 1982).

\section{Acknowledgments}

We thank Jun Hashimoto for the opportunity to join cruises N276 and N342; Captain Hiroshi Yoshimura, the crew, and researchers aboard TR/V Nagasaki-maru for support during the cruises. We would also like to acknowledge
Matthew H. Dick for reviewing and editing the manuscript. This study was supported in part by a KAKENHI grant (JP10J01119) to KK from the Japan Society for Promotion of Science (JSPS).

\section{References}

Akiyama, T., Shimomura, M., and Nakamura, K. 2008. Collection of deep-sea small arthropods: gears for collection and processing of samples on deck. Taxa 24: 27-32. [In Japanese with English abstract]

Bamber, R. N. 1992. Some pycnogonids from the South China Sea. Asian Marine Biology 9: 193-203.

Child, C. A. 1979. Shallow-water Pycnogonida of the Isthmus of Panama and the coast of Middle America. Smithsonian Contributions to Zoology 293: 1-86.

Child, C. A. 1988. Pycnogonida of the Western Pacific Islands, III: recent Smithsonian-Philippine expeditions. Smithsonian Contributions to Zoology 468: 1-32.

Dohrn, A. 1881. Die Pantopoden des Golfes von Neapel und der angrenzenden Meeres-Abschnitte. Monographie der Fauna und Flora des Golfes von Neapel 3: 1-252.

Nakamura, K. and Child, C. A. 1990. Pycnogonida of the Western Pacific Islands, VII. On some rare species from the Flores Sea, Indonesia. Proceedings of the Biological Society of Washington 103: 304-310.

Nakamura, K. and Child, C. A. 1991. Pycnogonida from waters adjacent to Japan. Smithsonian Contributions to Zoology 512: 1-74.

Sabroux, R., Corbari, L., Krapp, F., Bonillo, C., Le Prieur, S., and Hassanin, A. 2017. Biodiversity and phylogeny of Ammotheidae (Arthropoda: Pycnogonida). European Journal of Taxonomy 286: $1-33$.

Staples, D. A. 1982. Pycnogonida of the Calliope River \& Auckland Creek, Queensland. Memoirs of the Queensland Museum 20: 455-471.

Stock, J. H. 1954. Papers from Dr. Th. Mortensen's Pacific Expedition 1914-1916. LXXVII. Pycnogonida from Indo-West-Pacific, Australian, and New-Zealand waters. Videnskabelige Meddelelser fra Dansk Naturhistorisk Forening i København 116: 1-168.

Stock, J. H. 1985. Deux pycnogonides rares, récoltés pendant la campagne CORINDON II dans le détroit de Makassar, Indonésie. Bulletin Zoologisch Museum, Universiteit van Amsterdam 10: 153-158.

Wang, J., Xia, Z., Lin, R., Liang, Q., Lin, H., Wang, J., and Zheng, C. 2015. A new species of Hemichela Stock, 1954 from the South China Sea (Arthropoda, Pycnogonida, Ammotheidae). ZooKeys 526: $1-8$. 